\title{
Tiroid karsinomlarında kemik metastazlarına yaklaşım ve güncel tedaviler
}

\author{
Approach to bone metastases in thyroid carcinoma and current treatments
}

\author{
Barlas Göker, Mehmet Ayvaz \\ Hacettepe Üniversitesi Tıp Fakültesi, Ortopedi ve Travmatoloji Anabilim Dalı, Ankara
}

\begin{abstract}
Tiroid kanserine bağlı kemik metastazları, şiddetli ağrıya, spinal kord kompresyonuna ve patolojik kırıklara yol açabilen, kötü prognoz ile ilişkilendirilmiş lezyonlardır. Aksiyel iskelet başta olmak üzere pek çok bölgede sıklıkla osteolitik karakterde görülebilen bu tümörlerin görüntülemelerinde, son yıllarda tüm vücut bilgisayarlı tomografi ve manyetik rezonans yöntemleri öne çıkmıştır. Bisfosfonatlar ve denosumab gibi antirezorptif ilaçların iskelet ilişkili olayları azalttığı düşünülmektedir. Hastaların sadece üçte ikisi radyoaktif iyot ablasyonu tedavisine duyarlıdır ve $\% 46$ 'sı bu tedaviye tam yanıt vermektedir. Sorafenibin metastatik tiroid kanserlerinin tedavilerine onay alması ile birlikte, tirozin kinaz inhibitörleri de kemik lezyonlarının tedavisinde ön plana çıkmıştır. Cerrahi tedavide vertebroplasti ve sementoplasti gibi perkütan yöntemler yer alır. Spinal lezyonlarda cerrahi dekompresyon için uygun hastaların seçiminde NOMS Framework (nörolojik, onkolojik, mekanik, sistemik) kılavuzundan yararlanılabilir. Hipervasküler özellikte tümörler olmaları nedeniyle, cerrahi öncesi anjiyoembolizasyon önerilmektedir. Başka bölgede metastazı olmayan hastaların kemik lezyonları primer malign kemik tümörü gibi varsayılarak tedavi edildiğinde, sağkalımın ve fonksiyonel sonuç skorlarının arttığına dair veriler ortaya konmuştur.
\end{abstract}

Anahtar sözcükler: tiroid karsinomu; sorafenib; anjiyoembolizasyon; endoprotez

\begin{abstract}
Bone metastases due to thyroid cancer, which cause debilitating pain, spinal cord compression, and pathologic fractures are lesions mostly with poor prognosis. Whole body computerized tomography and magnetic resonance gained prominence in recent years in the imaging of these lesions which may present in various locations including the axial spine. Anti-resorptive drugs such as bisphosphonates and denosumab have been thought to reduce the incidence of skeletal related events. Only two thirds of patients are sensitive to radioactive iodine ablation therapy, and the full response rate is $46 \%$. After the approval of sorafenib for the treatment of metastatic thyroid cancer, thyrosine kinase inhibitors also gained popularity in the treatment of bone lesions. Percutaneous methods such as vertebroplasty and cementoplasty can be used in the surgical treatment. In patients with spinal lesions, NOMS Framework (neurological, oncological, mechanical, systemic) may help with the selection of the candidates which are better suited for surgical decompression. Angioembolization is recommended prior to surgery due to the hypervascular nature of these tumors. In patients with no other metastases, it has been shown that treating bone lesions as primary malignant bone tumors improves the survival and functional outcome scores.
\end{abstract}

Key words: thyroid carcinoma; sorafenib; angioembolization; endoprosthesis
T iroid karsinomlarının kemik metastazlarının tedavileri karmaşıktır ve bunlar sıklıkla kötü prognoz ile ilişkilendirilmiş lezyonlardır. Yüzde 80-95 olarak raporlanan diferansiye tiroid karsinomlarının 10 yıllık sağkalım oranları, kemik metastazları eşlik ettiğinde \%13-21 aralığına kadar düşebilmektedir. ${ }^{[1]}$ Hastalarda şiddetli ağrı ve patolojik kırıklara yol açabilen bu lezyonların tedavilerinde cerrahi de önemli bir role sahiptir. Bu derlemede, tiroid karsinomlarının tanı ve tedavisindeki güncel yaklaşımlar ile cerrahi prosedürleri incelemek ve yazarların bu konudaki deneyimlerini paylaşmak istedik.

\section{EPIDEMIYOLOJi}

Tiroid karsinomları, yıllar içerisinde sıklığında artış görülen malignensiler arasında yer alır; 2030 yılına gelindiğinde, ABD'de kolorektal kanserin yerini alarak, en sık görülen 4. kanser hastalığının tiroid kanserleri olacağı öngörülmektedir. ${ }^{[2]}$ Türkiye'de ise tiroid kanseri insidansı, erkeklerde 2,1/100.000, kadınlarda ise $8,8 / 100.000$ olarak raporlanmıştır. ${ }^{[3]}$

Tiroid karsinomlarının büyük çoğunluğu, diferansiye tiroid karsinomları (DTK) olarak kabul edilen papiller tiroid karsinomu (PTK) (\%70-75) ve foliküler tiroid

- İletişim adresi: Prof. Dr. Mehmet Ayvaz, Hacettepe Üniversitesi Tıp Fakültesi, Ortopedi ve Travmatoloji Anabilim Dalı, Ankara Tel: 0532 - 2203633 e-posta: mehmetayvaz@gmail.com

- Geliș tarihi: 23 Eylül 2019 Kabul tarihi: 22 Ekim 2019 
karsinomlarından (FTK) (\%15-20) oluşur. Bunların haricinde, medüller tiroid karsinomu (\%5-10), Hurthle hücreli karsinom (\%2) ve anaplastik karsinom varyantları da görülür. ${ }^{[4]}$ DTK'lerin \%2-13'ü arasında kemik metastazları görülürken, bunların içinde FTK'de \%7-28, PTK'de ise \%1,4-7 oranında kemik metastazları görülebilir. ${ }^{[1]}$

DTK’ler, başta omurga (\%34,6) olmak üzere, sıklıkla aksiyel iskelete metastaz yapar. Omurganın ardından metastaz yaptıkları diğer bölgeler, sırasıyla pelvis $(\% 25,5)$, toraks $(\% 18,3)$, ekstremiteler $(\% 10,2)$, omuz $(\% 5,4)$ ve kraniomaksillofasiyal kemiklerdir $(\% 5,4) \cdot{ }^{[5]}$ Okkült tiroid karsinomları, primeri bilinmeyen kemik metastazlarında genel olarak sık görülmemesine rağmen, bunlar özellikle omurgada saptanan metastatik lezyonlarda akla gelmesi gereken tümörlerdir.

\section{KLINIK GÖRÜNÜM}

Tiroid karsinomlarına bağlı kemik metastazları, hastalarda ağrı, patolojik kırıklar (\%13), radiküler ağrı (\%4) veya spinal kord kompresyonu ile (\%28) bulgu verebilir. ${ }^{[1,6]}$ Sırt ağrısı ile başvuran ve direkt grafisi bir patoloji lehine bulgular içeren hastaların \%60'ında, manyetik rezonans (MR) görüntülemede epidural tutulum saptanır. ${ }^{[1]}$

Kemik metastazları ile başvuran DTK hastalarının \%13-15'inde, eşlik eden akciğer metastazı da bulunur. Akciğer, her ne kadar \%49 ile uzak metastazların en sık görüldüğü organ olsa da; kemik tutulumu olan hastalarda 10 yıllık sağkalım (\%25) akciğer tutulumu olanlara (\%63) kıyasla daha düşüktür. ${ }^{[4]}$

\section{GÖRÜNTÜLEME}

Metastatik tiroid karsinomlarında kemik tutulumunun saptanması veya tespit edilen lezyonların ayrıntılı görüntülenmesi için; direkt grafi, bilgisayarlı tomografi (BT), MR, tüm vücut kemik sintigrafisi ve pozitron emisyon tomografi (PET) gibi yöntemler kullanılır. Tiroid karsinomlarında kemik metastazları çoğunlukla osteolitik özelliktedir; bu nedenle radyolojik yöntemlerde sıklıkla azalmış trabeküler kemik yoğunluğu ve düzensiz sınırlarla bulgu verir.

Boyutu $1 \mathrm{~cm}$ 'nin üzerinde olan lezyonlarda, destrüksiyon, skleroz, tümör infiltrasyonuna bağlı pediküllerin ortadan kaybolması gibi bulgular, direkt grafide görülebilir. BT ise, direkt grafiye kıyasla daha yüksek duyarlılığa sahip olmanın yanı sıra, multiplanar rekonstrüksiyon gibi modaliteler sayesinde, lezyonların üç boyutlu görüntülenmesine olanak sağlar. Tüm vücut düşüu doz BT tekniğinden yararlanarak da kemik survey'inden çok daha kısa sürede hastanın iskeletinde var olabilecek kemik metastazları taranabilir.
Günümüzde tümör görüntülemesinde büyük rol oynayan MR ise kemik, kemik iliği, yumuşak dokular ve lezyonların kemik dışına uzanımını göstermede direkt grafi ve BT'den daha yüksek duyarlılığa ve özgüllüğe sahiptir. ${ }^{[7]}$ Henüz kortekste destrüksiyona yol açmamış intramedüller metastatik lezyonlar MR ile görüntülenebilir. Ayrıca, vertebra tutulumu olan hastalarda kord kompresyonunu değerlendirmek ve vertebra çökme kırığı olan hastalarda kırık etiyolojisinin osteoporotik veya metastatik olup olmadığını araştırmada da MR'den yararlanılır.

Aksiyel iskeletin dışında yer alabilecek lezyonların saptanmasında, tüm vücut MR (TV-MR) kullanılan yöntemler arasındadır. Son yıllarda, özellikle diffüzyon ağılıklı TV-MR'nin (DA-TV-MR) tarama ve tedavi yanıtı değerlendirmede oldukça etkili olabileceğini öne süren çalışmalar ortaya çıkmıştır. Bir çalışmada, TV-MR, PET/ BT ve DA-TV-MR'nin, DTK'lerdeki kemik metastazlarını saptamadaki duyarıııkları karşılaştırılmış ve bunlar sırasıyla $\% 64, \% 79$ ve $\% 82$ olarak bulunmuştur. ${ }^{[8]}$

Özellikle osteoblastik karakterdeki iskelet metastazlarının taranmasında, nükleer tıp modaliteleri sıklıkla tercih edilir. ${ }^{[7]}$ Fakat, tiroid kanserlerinde kemik metastazları çoğunlukla osteolitik tipte görüldüğü için, yanlış pozitif ve yanlış negatif sonuç alınma ihtimali yüksektir. ${ }^{[1]}$ İyi diferansiye DTK'lerde ${ }^{123}$ | ve ${ }^{131}$ | tüm vücut tarama sintigrafileri ${ }^{99} \mathrm{~m} T \mathrm{Tc}-M D P ' y e$ (teknesyum 99m-metilendifosfonat) kıyasla daha duyarlı ve daha özgül olmasına rağmen, çoklu kemik metastazı olan hastalarda sıklıkla görülen kötü diferansiye karsinomlar için işe yaramaz. ${ }^{[1]}$

\section{TEDAVi}

Tiroid kanserlerine bağlı kemik metastazlarının tedavileri oldukça geniş bir yelpazeye sahiptir. Cerrahinin yanı sıra radyoaktif iyot (RAi) ablasyonu, dıştan odaklamalı radyoterapi (external beam radiotherapy -EBRT), kemoterapi ve osteolitik lezyonlar için bisfosfonatlar ile denosumab bu lezyonların tedavilerinde kullanılmaktadır. ${ }^{[9]}$

\section{Anti-rezorptif ilaçlar}

Tiroid karsinomlarına bağlı kemik metastazları çoğunlukla osteolitik karakterde olduklarından, bu lezyonlarda nükleer faktör-kappa $b$ reseptör aktivatör ligandı (RANK-L), interlökin-1 (IL-1), interlökin-6 (IL6) gibi sitokinlerin üretiminde artışa bağlı osteoklast aktivasyonu olur. ${ }^{[9]}$ Bisfosfonatlar ise osteoklastları inhibe ederek osteolitik lezyonlarda kemik destrüksiyonunun önüne geçebilir. Orita ve ark., zoledronik asit kullanan hastalarda kemik kırığı, kord kompresyonu ve hiperkalsemi gibi iskelet ilişkili olayları \%14, kullanmayanlarda ise $\% 50$ oranında saptamışlardır. ${ }^{[10]}$ Fakat 
aynı çalışmada, bisfosfonat kullanan hastalarda \%20 oranında hipokalsemi saptanmış ve \%32 oranında ağrı miktarında artış görülmüş̧tür. ${ }^{[10]}$ Vitale ve ark. ise, ayda bir infüzyon şeklinde pamidronat kullanan hastaların VAS (visual analog scale) skorlarında anlamlı düşüş saptamışlar, fakat bu grubun analjezik kullanımlarında anlamlı bir azalma görülmemiştir. ${ }^{[11]}$

Son yıllarda pek çok çalışma, denosumabın metastatik kemik hastalıklarının palyatif tedavisi için oldukça başarılı olduğunu göstermiştir. Her ne kadar tiroid kanserine bağlı kemik metastazları için kullanımı konusunda literatürde sınırlı çalışma olsa da; denosumab, multipl miyelom, akciğer, meme ve prostat kanserine bağlı kemik lezyonlarının tedavisinde yer edinmeye başlamıştır. Zhang ve ark. tarafından yapılan bir meta-analizde denosumab, zoledronik asit ile kıyaslandığında, iskelet ilişkili komplikasyonların önüne geçmede daha başarılı bulunmuştur. ${ }^{[12]}$ Chen ve ark. ise, bu iki ilacın güvenlik parametrelerini karşılaştırmışlar; yan etki profili benzer bulunmasına rağmen, denosumab kullanan hastalarda renal toksisite, hipokalsemi ve yeni primer malignite oluşumu gibi ciddi yan etkilerin, zoledronik asit kullananlara göre anlamlı bir şekilde daha düşük görüldüğünü saptamışlardır. ${ }^{[13]}$

\section{Radyoaktif Iyot Ablasyonu (RAi)}

DTK'lerin medikal tedavisinde olmazsa olmazlardan sayılan RAi, bu hastalıkların kemik tutulumlarının tedavisinde de yer alır. Kemik metastazlarının bir kısmı RAi tedavisine yanıt vermiyor olsa da, bu tedavinin hastanın ağrı palyasyonu ve prognozu açısından rolü büyüktür. Schlumberger ve ark.'na göre, kemik metastazlarına sahip tiroid kanseri hastalarının sadece $2 / 3^{\prime}$ 'ü ${ }^{131}$ l'e duyarlıdır ve $\% 46$ 'sı tedaviye tam yanıt vermektedir. Buna rağmen, beş yıllık sağkalımları karşılaştırıldığında tedaviye tam yanıt veren grup \%96 iken, öbür grup \%37 tespit edilmiştir. ${ }^{[14]}$

Mazziotti'nin çalışmasında, tümör hücrelerinin RAI'ye karşı aviditesinin iskelet ilişkili komplikasyonları istatistiksel olarak anlamlı bir derecede azalttığı ve RAi tedavisinin de sağkalımı artırdığı gösterilmiştir. ${ }^{[9]}$ Qiu ve ark., 45 yaş altı hastalarda ve PTK'lerde, ${ }^{131}$ I tedavisi sonrasında BT ve MR gibi anatomik görüntüleme yöntemlerinde tümör boyutunda anlamlı ölçüde azalma saptamışlardır. ${ }^{[15]}$

\section{Radyoterapi}

EBRT, kemik metastazlarının komplikasyonlarına karşı sıklıkla tercih edilen palyatif bir tedavi yöntemidir. Tümör boyutunu küçültücü etkisi sayesinde şiddetli ağrılara ve spinal kord kompresyonuna karşı etkili olmakta, patolojik kırıklar için kullanıldığında lokal rekürrensin önüne geçmektedir.

\section{Tirozin Kinaz İnhibitörleri}

Başlıca hedefleri VEGF, RET, BRAF ve c-Kit olan, çok hedefli tirozin kinaz inhibitörü sorafenib; renal hücreli karsinom ve hepatosellüler karsinomda kullanımına ilaveten, 2013 yılında metastatik tiroid kanserinin tedavisinde onay almıştır. ${ }^{[16]}$ RAI'ye dirençli tiroid kanseri hastalarında lenf nodu ve akciğer metastazlarına etkisi başarılı gösterilmiş olsa da, mevcut çalışmalar kemik lezyonlarına yönelik etkisinin minimal olduğu yönündedir. ${ }^{[16]}$

\section{Cerrahi Tedaviler}

Hastalara; tedaviye duyarsız şiddetli ağrı, RAi'ye dirençli tümörler, patolojik kırıklar veya artmış kırık riski, omurga instabilitesi veya spinal kord kompresyonu gibi nedenler için cerrahi girişim düşünülebilir. Standardize edilmiş kılavuzların yokluğu nedeniyle, cerrahi planlanırken tümörün lokalizasyonu, karakteri ve hastanın genel durumu gibi faktörler dikkate alınmalı ve hasta için en uygun cerrahi yöntem tercih edilmelidir. Küretaj ve polimetilmetakrilat (PMMA) ile çimentolamadan geniş rezeksiyon ve tümör endoprotezleri ile rekonstrüksiyona kadar uzanan pek çok farklı cerrahi seçeneği mevcuttur.

\section{Spinal metastazların cerrahi tedavisi}

Tiroid karsinomlarının en sık metastaz yaptığı bölge olan omurga lezyonları için radyofrekans (RF) ablasyon ve vertebroplasti/kifoplasti, spinal enstrümantasyon uygulanabilir. Perkütan yolla bir trokarı vertebra pedikülü aracılığıyla korpusa göndererek uygulanabilen vertebroplastide; kitleye PMMA çimento enjekte edilerek tedavi sağlanır. Minimal invaziv bir yöntem olduğundan, bu hasta grubunda ciddi morbiditeye yol açmadan, şiddetli ağrıların ve çökme kırıklarının tedavisinde kullanılabilir. Açık cerrahiyle kıyaslandığında daha güvenilir bir işlem olmasına rağmen, çimento kaçağına bağlı radikülopati, miyelopati gibi nörolojik komplikasyonlar ve pulmoner emboli gibi ciddi komplikasyonlara yol açabildiğinden, deneyimli hekimler tarafından dikkatlice yapılmalıdır. ${ }^{[17]}$

Tiroid karsinomlarının spinal metastazları hipervasküler tümörler olduğundan, eğer hastalara açık cerrahi ile dekompresyon ve spinal enstrümantasyon düşünülüyor ise, ameliyat öncesi girişimsel radyoloji tarafından anjiyoembolizasyon yapılmasında büyük yarar vardır. ${ }^{[18]}$ Bir meta-analize göre, hipervasküler spinal metastaz cerrahisinde ameliyat öncesi embolizasyon, ameliyat sırasındaki ortalama kan kaybını $1226 \mathrm{~mL}$ azaltarak anlamlı bir fark ortaya koymuştur. ${ }^{[19]}$ Kato ve ark., tiroid karsinomlarına bağlı spinal metastazların ameliyat öncesi embolizasyon sonrası, 
ameliyat sırasındaki ortalama kan kaybını $879 \pm 803$ $\mathrm{mL}$ hesaplamış. Aynı çalışmada, komplet embolizasyonun $(809 \pm 835 \mathrm{ml})$ kısmi embolizasyona göre $(1210 \pm 904 \mathrm{~mL})$ kan kaybını anlamlı ölçüde azalttığı $(p=0,03)$; embolizasyon günü yapılan cerrahinin $(879 \pm 854 \mathrm{~mL})$ sonraki gün yapılan cerrahiye göre $(1017 \pm 929 \mathrm{~mL})$ kanamayı azalttığı, fakat bu farkın istatistiksel olarak anlamlı olmadığı $(p=0,30)$ ortaya konmuştur. ${ }^{[18]}$

Açık cerrahi ise genellikle spinal instabilite ve nörolojik tutulumun eşlik ettiği ve sağkalım beklentisi daha yüksek olan hasta grubu için tercih edilmektedir. Cerrahi dekompresyona uygun hastaların seçimi için 2013'te Laufer ve ark., NOMS Framework (nörolojik, onkolojik, mekanik, sistemik) kılavuzunu geliştirmiştir. ${ }^{[20]}$ Bu algoritma için Spine Oncology Study Group'un (SOSG) geliştirdiği sınıflamada: nörolojik durum, tümörlerin radyoterapiye duyarlı veya dirençli olmasına göre; onkolojik durum, SOSG'nin geliştirdiği Spinal Instability Neoplastic Score'a (SINS) göre; mekanik instabilite, hastalığın yaygınlığı; komorbiditeler ve tümör histolojisine göre de sistemik durum belirlenir. Hastalar bu kategoriye göre incelendikten sonra, NOMS Framework şemasından yararlanılarak hastanın cerrahiye ya da radyoterapiye sevk edileceğine karar verilebilir.

Stabilizasyon için kullanılacak olan cerrahi teknik için posterior enstrümantasyon, interbody cage kullanımı, laminektomi, ve total en bloc spondilektomi gibi pek çok farklı seçenek mevcuttur. Hangi yöntemin uygulanacağına karar verilirken, hastanın ve tümörün karakteristik özellikleri göz önünde bulundurulur ve cerrah kendi deneyimli olduğu metotlardan hastaya en uygun olanını tercih eder. Yakın zamanda yapılmış bir sistematik derlemeye göre spinal metastaz cerrahisinde posterior yaklaşım ile yapılan laminektomi, transpediküler korpektomi ve kostotransversektomi arasında yapılan karşılaştırmada, ağrı palyasyonu, rekürrens ve sağkalım ölçütlerinin sonuçlarının benzer olduğu saptanmış ve aynı derlemede, daha büyük bir cerrahi olmasına rağmen, kostotransversektominin transpediküler korpektomiye göre daha az komplikasyon gösterdiği de görülmüşstür. ${ }^{[21]}$

Vertebra haricinde başka bir bölgede metastazın bulunmadığı hastalarda, vertebra metastazı primer spinal tümörler gibi tedavi edilebilir. Total en bloc spondilektomi, bu hasta grubunda sağkalımı ve nörolojik prognozu olumlu etkileyen ve lokal rekürrensin önüne geçmekte başarılı kabul edilen bir yöntemdir. Huang ve ark., L4 metastazına sahip dokuz hasta üzerinde posterior yaklaşım ile total en bloc spondilektomi uygulamış ve ortalama cerrahi süreyi 282 dakika (245-320), ortalama kanama miktarını ise $2421 \mathrm{~mL}(1900-3000)$ olarak saptamıştır. ${ }^{[22]}$

\section{Uzun kemik metastazlarının cerrahi tedavisi}

Tiroid kanserine bağıı uzun kemik metastazları hastalarda, şiddetli ağrının yanı sıra osteolitik özelliğe sahip olmaları nedeniyle, sıklıkla patolojik kırıklara da yol açabilmektedir. Bu lezyonlar saptandığında, Mirels'in geliştirdiği skorlama sisteminden yararlanılarak kırık riski hesaplanabilir ve hasta profilaktik olarak intramedüller çivileme gibi yöntemlerle tedavi edilebilir. ${ }^{[23]}$

Vertebra lezyonları için uygulanan vertebroplastiye benzer şekilde, uzun kemik lezyonları için de perkütan yolla sementoplasti uygulanabilir. Bu yöntem hastalar için düşük morbiditeye sahip olmakla birlikte, hastaların ağrı şiddetleri ve opiat analjezik ihtiyaçları açısından anlamlı ölçüde azalma da sağlamaktadır. ${ }^{[24]}$ Kim ve ark., 15 hastanın alt ekstremitelerindeki malign tümör metastazlarına yönelik perkütan sementoplasti ve esnek intramedüller çivileme işlemi uygulamışlar ve bunun bütün hastalarda ağrıda ve vizüel analog ölçek (VAS) skorlarında anlamlı azalma elde edildiğini, hastaların \%80'inde ise ambulasyon sağlandığını raporlamışlardır. ${ }^{[25]}$

Kemik metastazlarının cerrahi tedavilerinin sonuçlarına baktığımızda: hastaların ortalama \%82-99'unun ağrılarının azaldığı ve femur ile pelvis lezyonu olan hastaların \%83-99'unun mobilize olabildiğini görürüz. ${ }^{[26]}$ Fakat, hastaların bir kısmının ameliyat öncesi genel durumunun iyi olmaması, cerrahilerin genellikle çok kanamalı majör cerrahiler olması ve hastaların bir kısmının femur kırıkları gibi başlı başına mortalite ile ilişkili durumlar nedeniyle opere ediliyor olmaları, bu cerrahilerde sistemik komplikasyonların sık görülmesine neden olmaktadır. Bu komplikasyonlar arasında: derin ven trombozu, pulmoner emboli, pnömoni, konjestif kalp yetmezliği, sepsis ve çoklu organ yetmezliği gibi ölüm ile ilişkili olabilecek durumlar yer alır. ${ }^{[27]} \mathrm{Bir}$ sistemik derlemede, metastatik kemik hastalıklarının (meme, prostat, tiroid vb.) komplikasyon oranı ortalama \%13-23, mortalite oranı ise ortalama \%3-6 olarak bildirilmiştir. ${ }^{[26]}$

Proksimal femur metastazlarının cerrahi tedavi sonuçlarını karşılaştıran bir çalışmada, hastaların sırasıyla ameliyat öncesi ve ameliyat sonrası VAS ve MSTS (Musculoskeletal Tumor Society) skorları sırasıyla, megaprotezlerde VAS: 6,8/3,4 MSTS: 6,4/19,8, standart kalça protezlerinde VAS: 4,9/2,8 MSTS: $8,8 / 22,4$, gamma çivisi ve dinamik kalça çivisi ( $D H S$, dynamic hip screw) kullanılan grupta ise VAS: 6,9/5,1 MSTS: 10,8/18,2 olarak bulunmuştur. ${ }^{[28]}$ Aynı çalışmada, modüler endoprotez uygulanan hastaların ortalama sağkalımı (860 gün) internal tespit uygulanan hastaların sağkalımından (360 gün) daha yüksek bulunmuştur. 

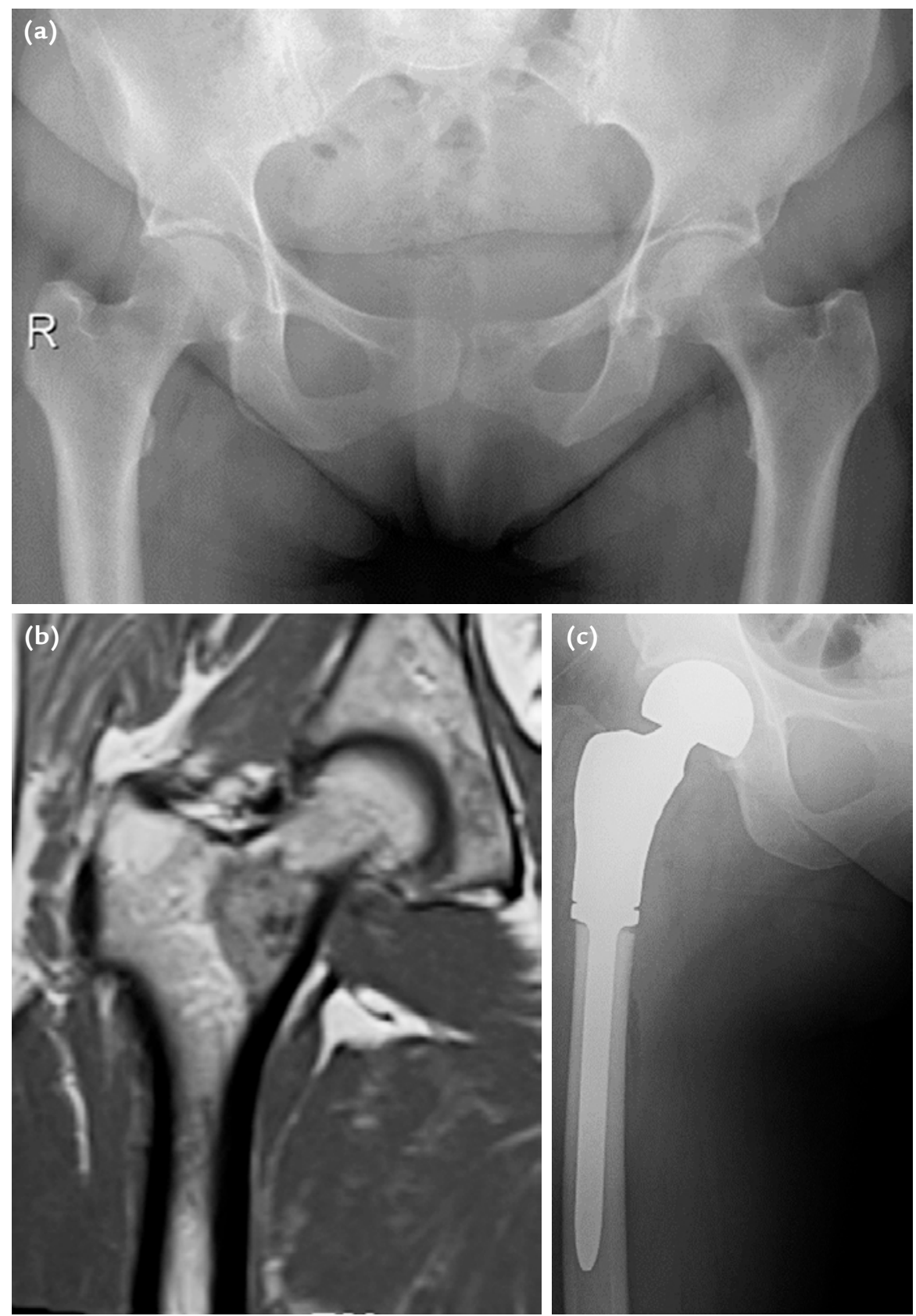

Şekil 1. a-c. Sağ kalça ağrısı ile başvuran ve sağ femur boynunda papiller tiroid karsinomu metastazı $(a, b)$ nedeniyle kliniğimizde tümör rezeksiyonu ve modüler tümör protezi ile rekonstrüksiyon (c) uygulanmış bir hastanın görüntüleri.

Proksimal femurun metastaza bağlı patolojik kırıkları nedeniyle, tedavi edilecek hastalarda dikkat edilmesi gereken bir başka husus ise hastanın yaşam beklentisidir. Hastaların sağkalımının hafife alındığı durumlarda, hastalara endoprotez yerine internal tespit tercih edilebilmektedir. Fakat, yapılan çalışmalar internal tespit uygulanan hastalarda kırık iyileşmesinin \%35'in altında olduğunu göstermiş, bu nedenle altı aydan fazla yaşayan hastalarda kaynamama (nonunion) ve implant yetmezliği gibi komplikasyonlar ortaya çıkmıştır. ${ }^{[27]}$ Endoprotez uygulanan hastalarda ise; implant sağkalımı daha yüksek ve revizyon cerrahisi gereği daha az iken, dislokasyon ve sistemik komplikasyonlara yatkınlık daha fazladır (Şekil 1).[ ${ }^{[27]}$ 


\section{SONUÇ}

Metastatik kemik hastalıklarının cerrahi yaklaşımları ve palyatif tedaviler, güncel literatürde yer tutmakta olup bilimsel gelişmelere oldukça açık konulardır. Tiroid karsinomlarına bağlı metastazlar değerlendirilirken; lezyonun bulunduğu bölge ve karakteristik özellikleri, hastaların semptomları, genel durumu ve sağkalım beklentisi iyi değerlendirilmelidir. Bu parametreler yardımıyla hastaya en uygun olan tedaviler belirlenmeli ve gerekirse tedavi multidisipliner bir ekip ile yönetilmelidir. Doğru hastaya doğru tedavi seçildiği zaman, medikal ve cerrahi tedavi yöntemleri başarılı ağrı palyasyonu sağlayabilmekte, hattâ sağkalımı artırabilmektedir.

\section{KAYNAKLAR}

1. Muresan MM, Olivier P, Leclere J, Sirveaux F, Brunaud L, Klein M, Zarnegar R, Weryha G. Bone metastases from differentiated thyroid carcinoma. Endocr Relat Cancer 2008;15(1):37-49. Crossref

2. Rahib L, Smith BD, Aizenberg R, Rosenzweig AB, Fleshman $J M$, Matrisian LM. Projecting cancer incidence and deaths to 2030: the unexpected burden of thyroid, liver, and pancreas cancers in the United States. Cancer Res 2014;74(11):291321. Crossref

3. Eser S, Yakut C, Özdemir R, Karakılınç H, Özalan S, Marshall SF, Karaoğlanoğlu O, Anbarcioğlu Z, Üçüncü $N$, Akin Ü, Özen E, Özgül N, Anton-Culver $H$, Tuncer M. Cancer incidence rates in Turkey in 2006: a detailed registry based estimation. Asian Pac J Cancer Prev 2010;11(6):1731-9. Erişim: http://journal.waocp.org/ article_25441_8bef9ae5ca5bf62c4c7818c6efd00706.pdf

4. Pal P, Singh B, Kane S, Chaturvedi P. Bone metastases in follicular carcinoma of thyroid. Indian J Otolaryngol Head Neck Surg 2018;70(1):10-4. Crossref

5. Osorio M, Moubayed SP, Su H, Urken ML. Systematic review of site distribution of bone metastases in differentiated. Head Neck 2017;39(4):812-8. Crossref

6. Bernier MO, Leenhardt L, Hoang C, Aurengo A, Mary JY, Meneagux F, Enkaoua E, Turpin G, Chiras J, Saillant G, Hejblum G. Survival and therapeutic modalities in patients with bone metastases of differentiated thyroid carcinomas. J Clin Endocrinol Metab 2001;86(4):1568-73. Crossref

7. O'Sullivan GJ, Carty FL, Cronin CG. Imaging of bone metastasis: An update. World J Radiol 2015;7(8):202-11. https://doi.org/10.4329/wjr.v7.i8.202

8. Stecco A, Trisoglio A, Soligo E, Berardo S, Sukhovei L, Carriero A. Whole-Body MRI with Diffusion Weighted Imaging in Bone Metastases: A Narrative Review. Diagnostics (Basel) 2018;8(3). Crossref

9. Mazziotti G, Formenti AM, Panarotto MB, Arvat E, Chiti A, Cuocolo A, Dottorini ME, Durante C, Agate L, Filetti S, Felicetti F, Filice A, Pace L, Pellegrino T, Rodari M, Salvatori M, Tranfaglia C, Versari A, Viola D, Frara S, Berruti A, Giustina A, Giubbini R. Real-life management and outcome of thyroid carcinoma-related bone metastases: results from a nationwide multicenter experience. Endocrine 2018;59(1):90-101. Crossref
10. Orita Y, Sugitani I, Takao S, Toda K, Manabe J, Miyata S. Prospective evaluation of zoledronic acid in the treatment of bone metastases from differentiated thyroid carcinoma. Ann Surg Oncol 2015;22(12):4008-13. Crossref

11. Vitale G, Fonderico F, Martignetti A, Caraglia M, Ciccarelli A, Nuzzo V, Abbruzzese A, Lupoli G. Pamidronate improves the quality of life and induces clinical remission of bone metastases in patients with thyroid cancer. $\mathrm{Br} J$ Cancer 2001;84(12):1586-90. Crossref

12. Zhang Z, Pu F, Shao Z. The skeletal related events of denosumab versus zoledronic acid in patients with bone metastases: A meta-analysis of randomized controlled trials. J Bone Oncol 2017;9:21-4. Crossref

13. Chen F, Pu F. Safety of Denosumab versus zoledronic acid in patiens with bone metastases: a meta-analysis of randomized controlled trials. Oncol Res Treat 2016;39(7-8):453-9. Crossref

14. Schlumberger $M$, Challeton C, De Vathaire F, Travagli JP. Gardet P, Lumbroso JD, Francese C, Fontaine F, Ricard M, Parmentier C. Radioactive iodine treatment and external radiotherapy for lung and bone metastases from thyroid carcinoma. J Nucl Med 1996;37(4):598-605. Erişim: http:// jnm.snmjournals.org/content/37/4/598.long

15. Qiu ZL, Song HJ, Xu YH, Luo QY. Efficacy and survival analysis of 131 l therapy for bone metastases from differentiated thyroid cancer. J Clin Endocrinol Metab 2011;96(10):307886. Crossref

16. Ferrari SM, Politti U, Spisni R, Materazzi G, Baldini E, Ulisse S, Miccoli P, Antonelli A, Fallahi P. Sorafenib in the treatment of thyroid cancer. Expert Rev Anticancer Ther 2015;15(8):86374. Crossref

17. Kushchayev S, Kushchayeva Y, Theodore N, Preul MC, Clark $\mathrm{OH}$. Percutaneous vertebroplasty for thyroid cancer metastases to the spine. Thyroid 2010;20(5):555-60. Crossref

18. Kato S, Hozumi T, Takaki Y, Yamakawa K, Goto T, Kondo T. Optimal Schedule of preoperative embolization for spinal metastasis surgery. Spine 2013;38(22):1964-9. Crossref

19. Luksanapruska P, Buchowski JM, Tongsai S, Singhatanadgige $W$, Jennings JW. Systematic review and meta-analysis of effectiveness of preoperative embolization in surgery for metastatic spine disease. J Neurointerv Surg 2018;10(6):596601. Crossref

20. Laufer I, Rubin DG, Lis E, Cox BW, Stubblefield MD, Yamada $\mathrm{Y}$, Bilsky $\mathrm{MH}$. The NOMS framework: approach to the treatment of spinal metastatic tumors. Oncologist 2013;18(6):744-51. Crossref

21. Molina C, Goodwin CR, Abu-Bonsrah N, Elder BD, De la Garza Ramos R, Sciubba DM. Posterior approaches for symptomatic metastatic spinal cord compression. Neurosurg Focus 2016;41(2): E11. Crossref

22. Huang W, Wei H, Cai W, Xu W, Yang X, Liu T, Wu Z, Huang Q, Yan W, Xiao J. Total en bloc spondylectomy for solitary metastatic tumors of the fourth lumbar spine in a posterior-only approach. World Neurosurg 2018;120:e816. Crossref

23. Mirels $\mathrm{H}$. Metastatic disease in long bones: a proposed scoring system for diagnosing impending pathologic fractures. Clin Orthop Relat Res 1989;(249):256-64. Crossref

24. Botton E, Edeline J, Rolland $\mathrm{Y}$, Vauléon E, Roux CL, Mesbah $\mathrm{H}$, Porée P, Audrain O, Raoul JL. Cementoplasty for painful bone metastases: a series of 42 cases. Med Oncol 2012;29(2):1378-83. Crossref 
25. Kim Y, Kang HG, Kim TS, Kim S, Kim JH, Kim HS. Palliative percutaneous stabilization of lower extremity for bone metastasis using flexible nails and bone cement. Surg Oncol 2014;23(4):192-8. Crossref

26. Wood TL, Racano A, Yeung $H$, Farrokhyar F, Ghert $M$, Deheshi BM. Surgical management of bone metastases: quality of evidence and systemic review. Ann Surg Oncol 2014;21(13):4081-9. Crossref
27. Di Martino A, Martinelli N, Loppini M, Piccioli A, Denaro V. Is endoprosthesis safer than internal fixation for metastatic disease of the proximal femur? A systematic review. Injury 2017;48:S48-54. Crossref

28. Guzik G. Oncological and functional results after surgical treatment of bone metastases at the proximal femur. BMC Surg 2018;18(1). Crossref 